\title{
Direct molecular analysis of myotonic dystrophy in the German population: important considerations in genetic counselling
}

Institute of Human Genetics,

University of Leipzig, Germany

A Meiner

C Wolf

E Kunert

Genetics Unit,

Department of

Anatomy,

Charing Cross and

Westminster Medical

School,

London, UK

N Carey

A Okitsu*

K Johnson

P Shelbourne†

Neurological Clinic,

Technical University

of Dresden,

Medical Faculty,

Germany

B Kunath

W Sauermann

Institute of Human

Genetics and Medical

Biology,

University of Halle-

Wittenberg,

Germany

$\mathrm{H}$ Thiele

Praxis fur

Humangenetik,

Marienstrasse,

Cottbus,

Germany

P Kupferling

* Present address:

Department of Neurology, Tokyo Kita Medical Rehabilitation Centre, Tokyo, Japan.

†Present address: Department of Genetics, Stanford University School of Medicine, Stanford,

CA 94305, USA.

Correspondence to:

Dr Kunert,

Alte Salzstrasse 104,

D-04209 Leipzig,

Germany.

Received 30 January 1995 Revised version accepted for publication 29 March 1995

A Meiner, C Wolf, N Carey, A Okitsu, K Johnson, P Shelbourne, B Kunath, W Sauermann, $H$ Thiele, P Kupferling, E Kunert

\begin{abstract}
Myotonic dystrophy (DM) is associated with the expansion and instability of a trinucleotide (CTG) repeat at the DM locus on chromosome 19. Direct genomic analysis in the German population was carried out on $18 \mathrm{DM}$ families, six families with equivocal diagnosis, 69 subjects with equivocal clinical diagnosis, and 100 controls using the polymerase chain reaction (PCR) and a refined Southern protocol.

In the majority of the cases molecular analysis confirmed the clinical diagnosis. These included seven cases of congenital DM (CDM) with widely differing gene expansions and instabilities. In most $D M$ families the expanded fragment became larger in successive generations, but we also identified four families with contractions and two families that showed stability of the enlarged fragment during transmission.
\end{abstract}

In four clinically defined DM patients we were unable to detect enlarged CTG repeats. Sequencing of each exon of the $D M$ gene in two of these patients failed to show any mutations.

Our cases have important implications for genetic counselling of DM families, highlighting both the diagnostic value of direct genomic analysis and its limitations.

( $($ Med Genet 1995;32:645-649)

DM, also known as Curschmann-Steinert disease, is an autosomal dominant disorder and the most frequent form of adult muscular dystrophy with a minimal incidence of 1 in 8000 in the European population. ${ }^{1}$ The penetrance is high and new mutations are rare. The clinical picture varies within and between families. Common symptoms are progressive muscle weakness, wasting, and myotonia characterising $\mathrm{DM}$ as a neuromuscular disease. However, a variety of other systems can be involved and symptoms include cataracts, cardiac arrhythmias, smooth muscle involvement, brain alterations, hypersomnia, and abnormal glucose response. ${ }^{1}$ In males, premature frontal balding and testicular atrophy may be present and in females ovarian insufficiency and many other symptoms may be detectable. ${ }^{1}$ Anticipation, the phenomenon in which symptom severity increases and age of symptom onset falls in succeeding generations of a disease pedigree, is a characteristic feature of $\mathrm{DM}^{2}$
$D M$ is caused by the expansion and instability of a CTG trinucleotide repeat in the $3^{\prime}$ untranslated region of a gene at $19 \mathrm{q} 13.2-13.3$, encoding a putative cAMP dependent protein kinase (DMPK). ${ }^{3}$ In the normal population the CTG copy number ranges from five to about $37,{ }^{4}$ but in DM patients there are extreme expansions up to 4000 copies. ${ }^{5}$ There are no reports of the normal range overlapping with the minimal repeat number associated with the DM phenotype. There is a broad correlation of symptom severity with expansion size, although this is more readily observable within rather than between pedigrees. ${ }^{6}$

In the majority of reported cases the CTG expansion increases in size with transmission in a DM pedigree. This may act as a molecular basis for anticipation, ${ }^{2}$ greater expansion sizes being generally associated with increasing symptom severity. ${ }^{6}$ However, there are a number of reports of contraction of the repeat upon transmission, mainly paternally. ${ }^{5-10}$ It is also possible that stable transmissions of relatively small expansions are underestimated owing to ascertainment biases. ${ }^{11}$

The amplified CTG repeat region shows both meiotic and mitotic instability. The somatic mosaicism resulting from mitotic instability is characterised by a diffuse smear of fragments harbouring expanded repeats, occurring at least in blood leucocytes generally used for DNA extraction, ${ }^{12-14}$ whereas the differences in size within one generation of a DM family may be explained by meiotic instability of germline mosaicism.

\section{Materials and methods}

DNA ANALYSIS

Genomic DNA was isolated from peripheral blood samples according to Miller et al. ${ }^{15}$ The DNA was analysed for the expansion by Southern blotting using cDNA probes p5B1.4 and p25B1.4, as previously described. ${ }^{10}$ The probes were radiolabelled using $\left[{ }^{32} \mathrm{P}-\alpha\right] \mathrm{dCTP}$ by random labelling. ${ }^{16}$ Expanded fragments were sized by measuring the midpoint of the band, and recording its upper and lower extremes, as larger bands tend to be diffuse owing to somatic heterogeneity.

PCR ANALYSES AND SEQUENCING

PCR ampification of the CTG repeat region was performed using the conditions described by Brook et $a l^{17}$ with primers 101 and 102, One 
Table 1 PCR primers and conditions for amplification of all exons of the DMPK gene. All the primers are located in intronic regions in order to generate the entire exons

\begin{tabular}{|c|c|c|}
\hline $\operatorname{Exon}(s)$ & $\begin{array}{l}\text { Fragment } \\
\text { size }(b p)\end{array}$ & $\begin{array}{l}\text { Primer sequence } \\
(F=\text { forward } R=\text { reverse })\end{array}$ \\
\hline 1 & 668 & $\begin{array}{l}\text { F:5' GTTGCTACTGGGTCACTCAGC 3' } \\
\text { R:5' CTCTGTGCCCAGAGCTGTCT } 3^{\prime}\end{array}$ \\
\hline $2,3,4$ & 750 & $\begin{array}{l}\text { F:5' CTTGTCTCCAAGTGCCCTTTC } 3^{\prime} \\
\text { R:5' TCCTAGAGCTTCCTCTCCCC } 3^{\prime}\end{array}$ \\
\hline 5,6 & 622 & $\begin{array}{l}\text { F:5' CTCAGGGGACTACCAACCAC } 3^{\prime} \\
\text { R:5' ACACTCTGTGCCTTCCATCC } 3^{\prime}\end{array}$ \\
\hline 7,8 & 699 & $\begin{array}{l}\text { F:5' TAAGCATTTGGGGAGTGGTT } 3^{\prime} \\
\text { F:5' CCAACTTTATGGAGGGAGCA } 3^{\prime}\end{array}$ \\
\hline 9 & 183 & $\begin{array}{l}\text { F:5' ACTGCTCGTCACATCTGTGTG 3' } \\
\text { R:5' AGGAGCAGGACCCAGGAAG 3' }\end{array}$ \\
\hline 10 & 198 & $\begin{array}{l}\text { F:5' ATTCTGTCTCCCTCCCCACT } 3^{\prime} \\
\text { R:5' TTCTCTCCCAATTGTCCCTG 3' }\end{array}$ \\
\hline $11,12,13$ & 781 & $\begin{array}{l}\text { F:5' CCTGGAACCAGTGTCCAAGT } \\
\text { R:5' AGGGCTTCTGCCCTCTAAAG } 3^{\prime}\end{array}$ \\
\hline 14 & 394 & $\begin{array}{l}\text { F:5' ATCTCCCTCCGTTCAGGC } 3^{\prime} \\
\text { R:5' GTCATTGGCTGCTTCCTAGC } 3^{\prime}\end{array}$ \\
\hline 15 & 721 & $\begin{array}{l}\text { F:5' CCACCTATGGGCGTAAGGC } 3^{\prime} \\
\text { R:5' TTTGGCAAAGCAAATTTCC } 3^{\prime}\end{array}$ \\
\hline
\end{tabular}

Exon 2, 3, 4 internal sequencing primer: 5' AAGCGGGTGGAGTTGGGTCT 3'.

PCR conditions: $200 \mathrm{ng}$ genomic DNA, 50 pmol primer, $200 \mu \mathrm{mol} / 1 \mathrm{dNTP}, 67 \mathrm{mmol} / 1 \mathrm{Tris}-\mathrm{HCl}$ $\mathrm{pH} 8.8,16.6 \mathrm{mmol} / 1\left(\mathrm{NH}_{4}\right)_{2} \mathrm{SO}_{4}, 2 \mathrm{mmol} / 12.5 \mathrm{mmol} / 6.7 \mathrm{mmol} / 1 \mathrm{MgCl}_{2}, 10 \mathrm{mmol} / 1 \beta \mathrm{mer}$ captoethanol, $6.7 \mu \mathrm{mol} / 1 \mathrm{EDTA}, 1$ unit Taq polymerase in a total reaction volume of $50 \mu \mathrm{l}$. Initia denaturation step of $95^{\circ} \mathrm{C}$ for five minutes, followed by 30 cycles of $95^{\circ} \mathrm{C}$ for 90 seconds, $60^{\circ} \mathrm{C}$ for 90 seconds, $72^{\circ} \mathrm{C}$ for three minutes, with a final elongation step of $72^{\circ} \mathrm{C}$ for seven minutes.

fifth of each PCR product was electrophoresed on a $10 \%$ polyacrylamide gel and visualised by ethidium bromide staining with UV transillumination.

The 15 exons of the DMPK gene were amplified using the primer pairs and conditions shown in table 1 . PCR products were purified by low gelling temperature agarose electrophoresis, followed by extraction with hot phenol to isolate the DNA. The PCR product was sequenced using the PRISM Ready Reaction DyeDeoxy Terminator Cycle Sequencing Kit (Applied Biosystems Inc) with one of the PCR primers as a sequencing primer. For one of the PCR products it was also necessary to design an internal sequencing primer. The DNA sequences were generated on an Applied Biosystems Model 373A Sequencing System and the sequence data were analysed using the Seqed and AssemblyLign programs from Applied Biosystems Inc.

\section{PATIENTS}

Twenty four families (121 subjects) were investigated, comprising 18 families ( 108 subjects including 51 patients at risk) with a definite clinical diagnosis of DM (by the criteria of Griggs $e t a l^{18}$ and Koch et $a l^{19}$ and six families (13 subjects) with a clinically equivocal DM diagnosis. In the majority of cases full clinical data were available. In addition, blood samples from a further 69 subjects (35 of whom had

Table 2 Analysis of transmission of congenital DM (CDM) in the German population. Expansion sizes were estimated by Southern blotting, using the enzyme BglI and probes p5B1.4 or p25B1.4. Sharp bands were detected in cases 3, 4, and 7. Family numbers are shown after the CDM case number, when these cases have appeared in other tables in this paper. The age at DNA sampling is given. Note the very small maternal expansion in case 1

\begin{tabular}{llllll}
\hline & \multicolumn{2}{l}{ Mother } & & \multicolumn{2}{l}{$C D M$ child } \\
\cline { 2 - 3 } \cline { 5 - 6 } Case No & Expansion $(k b)$ & Age & & Expansion $(k b)$ & Age \\
\hline 1 & $0 \cdot 6-0 \cdot 7$ & $49 \mathrm{y}$ & & $2 \cdot 0-2 \cdot 3$ & $28 \mathrm{y}$ \\
$2(13)$ & $4 \cdot 7-5 \cdot 7$ & $35 \mathrm{y}$ & & $3 \cdot 5-4 \cdot 0$ & $24 \mathrm{y}$ \\
3 & $2 \cdot 1-3 \cdot 5$ & $28 \mathrm{y}$ & & $5 \cdot 5$ & $2 \mathrm{mth}$ \\
4 & $1 \cdot 6-2 \cdot 0$ & $24 \mathrm{y}$ & & $5 \cdot 4$ & $1 \mathrm{mth}$ \\
5 & $1 \cdot 7-2 \cdot 4$ & $21 \mathrm{y}$ & & $3 \cdot 9-4 \cdot 1$ & $6 \mathrm{mth}$ \\
6 & $4 \cdot 5-5 \cdot 0$ & $34 \mathrm{y}$ & & $6 \cdot 5-7 \cdot 0$ & $8 \mathrm{y}$ \\
$7(16)$ & $2 \cdot 4-3 \cdot 0$ & $26 \mathrm{y}$ & & $4 \cdot 1$ & $2 \mathrm{mth}$ \\
\hline
\end{tabular}

received a definite clinical diagnosis of DM, and 34 an equivocal diagnosis) were analysed. These samples had been sent from neurological clinics throughout Germany for molecular diagnosis. The control group was composed of 100 healthy, randomly chosen volunteer donors from eastern Germany between 16 and 60 years of age, with an approximately equal ratio of males to females.

\section{Results}

CTG REPEAT ALLELE DISTRIBUTION IN THE CONTROL POPULATION

The distribution of alleles in the non-DM population showed no obvious differences from the previously reported figures for the European population $^{4}$ (data not shown). The highest repeat number observed was 37 repeats.

\section{EXPANDED DM ALLELES}

Expansions of the CTG repeat were found in 18 families diagnosed clinically with DM. All patients with minimal symptoms had CTG expansions of less than $0.5 \mathrm{~kb}$. Classical DM appears to be associated with a very wide range of expansion sizes, ranging from $0.6 \mathrm{~kb}$ to $5.7 \mathrm{~kb}$. Of the seven congenitally affected patients in this study (table 2 ) three had very large expansions of over $5 \mathrm{~kb}$, while four had smaller expansions, in a range which can also be associated with classical symptoms.

Extensive smearing was found on the Southern blots of the large expansions from the classically affected cases and in the adult CDM cases, suggesting widespread somatic heterogeneity in peripheral blood leucocytes. The smears ranged in size from $0.1 \mathrm{~kb}$ to $2.0 \mathrm{~kb}$. Very little smearing could be detected for either the minimal expansions or, interestingly, for the three severely affected CDM neonates (table 2). These presented with very sharp expanded bands of approximately $5.5 \mathrm{~kb}$, $5.4 \mathrm{~kb}$, and $4 \cdot 1 \mathrm{~kb}$ on Southern blotting, when using the restriction enzyme $B g I$ (data not shown).

\section{CHANGES IN CTG EXPANSION SIZE ON} TRANSMISSION

In the 18 families available for study, increases in the size of the expanded fragment were found

Table $3 D M$ families in which there has been contraction $(A)$ or stability $(B)$ of transmission of expanded CTG repeats. Expansion sizes were estimated by Southern blotting, using the enzyme BglI and probes $p B 1.4$ or p25B1.4

\begin{tabular}{lll}
\hline Family No & Expansion sizes $(\mathrm{kb})$ & Transmission change $(\mathrm{kb})$ \\
\hline (A) & Mother $(4 \cdot 7-5 \cdot 7)$ & $-1 \cdot 2-1 \cdot 7$ \\
13 & Son $(3 \cdot 5-4 \cdot 0)$ & $-1 \cdot 3-1 \cdot 8$ \\
14 & Mother $(3 \cdot 0-3 \cdot 9)$ & $-0.6-0.8$ \\
15 & Son $(1 \cdot 7-2 \cdot 1)$ & \\
& Father $(2 \cdot 5-3 \cdot 3)$ & Son $(1 \cdot 9-2 \cdot 5)$ \\
16 & Father $(1 \cdot 0-1 \cdot 4)$ & $-0 \cdot 4-0.1$ \\
(B) & Son $(0 \cdot 9-1 \cdot 0)$ & \\
17 & Father $(0 \cdot 7-1 \cdot 7)$ & $-0 \cdot 3-+0 \cdot 4$ \\
18 & Son $(1 \cdot 1-1 \cdot 4)$ & 0 \\
& Mother $(2 \cdot 0-2 \cdot 5)$ & \\
\hline
\end{tabular}


Table 4 Major symptoms in two unrelated female patients with a clinical diagnosis of DM but no CTG expansion

\begin{tabular}{|c|c|c|}
\hline & Case 1 & Case 2 \\
\hline Myotonia & $\begin{array}{l}\text { Grip (slight) } \\
\text { Percussion (slight) } \\
\text { DM typical by EMG } \\
\text { Predominantly proximal } \\
\text { Severe ptosis }\end{array}$ & $\begin{array}{l}\text { Grip } \\
\text { Percussion } \\
\text { DM typical by EMG } \\
\text { Predominantly proximal } \\
\text { Severe facial myotonia }\end{array}$ \\
\hline Muscle atrophy & $\begin{array}{l}\text { Predominantly proximal } \\
\text { Sternocleidomastoid involvement }\end{array}$ & $\begin{array}{l}\text { Predominantly proximal } \\
\text { Sternocleidomastoid involvement }\end{array}$ \\
\hline $\begin{array}{l}\text { Serum CK } \\
\text { Muscle biopsy } \\
\text { Ocular findings } \\
\text { Endocrine findings }\end{array}$ & $\begin{array}{l}\text { Normal } \\
\text { Not performed } \\
\text { Typical bilateral DM cataracts } \\
\text { Goitre } \\
\text { Diabetes mellitus }\end{array}$ & $\begin{array}{l}\text { Normal } \\
\text { Not performed } \\
\text { Bilateral retinal ablation } \\
\text { Goitre }\end{array}$ \\
\hline $\begin{array}{l}\text { Gynaecology } \\
\text { Cardiac findings } \\
\text { Mental retardation } \\
\text { Other symptoms } \\
\text { Age of onset }\end{array}$ & $\begin{array}{l}1 \text { miscarriage } \\
\text { Possible left ventricular hypertrophy } \\
\text { Possible slight retardation } \\
\text { Hypersomnia } \\
\text { Upper limb myotonia at } 30 \mathrm{y} \\
\text { Lower limb myotonia at } 50 \mathrm{y} \\
\text { Weakness in 5th-6th decades } \\
\text { Hypersomnia in early 2nd decade }\end{array}$ & $\begin{array}{l}1 \text { ectopic pregnancy } \\
\text { Grade } 1 \text { atrioventricular block } \\
\text { Not stated } \\
\text { Hypersomnia } \\
\text { Most symptoms noticed in } 4 \text { th decade } \\
\text { Hypersomnia at a much earlier but } \\
\text { unspecified point }\end{array}$ \\
\hline Family history & Clinically affected son & Clinically affected son \\
\hline
\end{tabular}

in 12 families (data not shown), decreases were found in four and in two families there were no major changes in expansion size on transmission. The sample numbers are too small to determine if there is a statistically significant difference in the pattern of transmission through the male and female lines, as has been previously reported. ${ }^{20}$

The increases in expansion size range from $+0.3 \mathrm{~kb}$ to $+3.7 \mathrm{~kb}$ and in these families there is broad correlation between symptom severity and the change in fragment size, although there are interesting exceptions to this general trend. In one family two sons with very similar sized expansions in the DNA of their peripheral blood leucocytes show marked differences in their symptoms. Both have inherited expansions of approximately $1-2 \mathrm{~kb}$ from their minimally affected mother. The older son, who is now 32 years old, first noticed clinical symptoms at 26 years of age, and has been diagnosed as classically affected. His brother is two years younger and is subjectively asymptomatic, although slight myotonic signs on EMG and the initiation of bilateral myotonic cataracts have been noted clinically.

Table $3 \mathrm{~A}$ and $\mathrm{B}$ summarise those cases in which the expanded fragment either remained stable or contracted in size on transmission. In each of families 13 to 16 there is at least one transmission event in which there has been a decrease in fragment size, but in each case this has been accompanied by clinical anticipation. In one case, family 13 , the child who has inherited the contraction from his mother presented with CDM (CDM case 2, table 2). The mother had first noticed muscle weakness at 13 years of age and myotonia at 16 . She is now 54 years old and has severe classical DM, with marked muscle involvement. She is unable to walk. The son shown in table $3 \mathrm{~A}$ was born with CDM and is now 24 years old. His symptoms include mental retardation, myotonia, cataract, club foot, and other symptoms of classical DM. He has no detectable myopathy.

In family 14 , the mother shown in table $3 \mathrm{~A}$ has distinct myotonia and remarkable myopathy. She developed her symptoms in early adulthood and is now unable to walk. Her 12 year old son, who has inherited a contracted allele from her, has severe early childhood onset
DM, with mental retardation and an inability to walk since early childhood.

In families 17 and 18 there was considerable overlap of the ranges of the expansions in the affected family members and it was not possible to show a clear trend in the behaviour of the expansion in these pedigrees. Clinical anticipation was apparent in family 17 , where the father has classical DM with myotonia (only detectable by EMG) and an age at onset of approximately 40 years. The son, shown in table $3 \mathrm{~B}$, has remarkable myotonic discharges on EMG and began presenting with classical DM symptoms at the age of 17 years.

Owing to small family sizes we were unable to investigate multiple transmission events in these pedigrees. It is therefore unclear if the predominant transmission of contractions/ stable expansions to sons is simply an artefact of our data.

There were no examples in our families of contractions from the pathological back into the normal range.

\section{ANALYSIS OF EQUIVOCAL CASES}

In six families in which DM had been suggested on clinical grounds no expansions of the CTG repeat could be shown at the molecular level. As a consequence the families were reanalysed clinically and alternative diagnoses were made, including Peno-Shokeir syndrome I (arthrogryposis multiplex congenita) and congenital myopathy associated with malignant hyperthermia.

In certain cases we had access only to blood samples from subjects with suspected DM; no samples were available from other family members. There were 69 such patients, of whom 35 had been "definitely" diagnosed with $\mathrm{DM}$, and for the remaining 34 the clinical diagnosis was equivocal. In the "equivocal" group the DM diagnosis was confirmed for five $(14.7 \%)$ of these patients. In the remaining patients in this group other diagnoses were reached by the clinicians after receipt of this molecular information. In the "definite" group the diagnosis was confirmed in 31 patients $(88.6 \%)$. However, in the remaining four patients two normal CTG alleles were present, yet clinical reassessment after the molecular 
analysis still indicated DM as the most appropriate diagnosis. Clinical data for two of these four "non-expansion DM" patients are presented in table 4. Each exon of the DMPK gene was sequenced in these two patients but no mutations were detected.

\section{Discussion}

This study confirms and extends previous observations on both the normal and expanded DM alleles, focusing exclusively on the German population. It confirms previous reports that contraction of the repeat is a much more common phenomenon than had originally been expected, ${ }^{5-10}$ although in this case the numbers are too small to confirm the apparent male bias in this effect.

The data reported here clearly show that the correlation between expansion size and symptom severity is broad rather than absolute, illustrating the difficulties which surround not only prenatal diagnosis but also predictive estimation of disease severity based on expansion size. At its most extreme form transmission of a contracted allele was associated with clinical presentation with CDM, a phenomenon which has only been reported once previously, when an $8 \mathrm{~kb}$ expansion in a classically affected mother was transmitted as a $4 \mathrm{~kb}$ expansion to a congenitally affected child. ${ }^{9}$ The implications of this finding, particularly for prenatal diagnosis, cannot be overstressed.

It is interesting that in all reported cases in which biopsy material has been analysed larger expansions have always been found in the muscle tissue than the blood of affected subjects. ${ }^{2122}$ It would be interesting to examine the expansion in the muscles of the parent-child pairs in whom contractions have been associated with clinical anticipation. The symptomatically discordant brothers who have very similar repeat sizes would also be interesting subjects for an analysis of tissue heterogeneity, to determine if muscle expansions are more reliable predictive indicators.

The lack of detectable somatic heterogeneity in the peripheral blood leucocytes from neonatal congenital cases, compared with adult cases, may suggest that this heterogeneity is established after birth and may be a continuing process throughout life. It will be of great interest to perform a prospective longitudinal study on the expansion in the leucocytes from these congenital cases to determine at what point the somatic heterogeneity in this tissue becomes established, and whether it arises solely through continued enlargement of the expansion, contraction, or both. Interestingly, no detectable progression has been reported in muscle biopsy samples taken over a 15 year period, ${ }^{21}$ although it has yet to be formally proven that this lack of progression was not an artefact of the gel system used.

$\mathrm{DM}$ is considered one of the most genetically homogeneous diseases, with over $99 \%$ of cases being caused by the CTG expansion. There is very strong evidence for a founder chromosome effect in this disorder ${ }^{23}$ and no new mutations have been found. It is anticipated that in the cases reported here in which the expansion was identified in isolated cases other family members will almost certainly present with minimal expansions and very mild symptoms.

It was unexpected that in four of our cases in which two normal alleles were identified at the DM locus there remained a clinically definite diagnosis of DM. As shown in table 4 these fulfil all recognised criteria for diagnosis of DM, and this remained the most appropriate clinical assessment at the point of examination. It is possible, however, that these patients may represent cases related to the recently described PROMM syndrome, ${ }^{24}$ although in the absence of a known mutation(s) underlying this disorder this hypothesis cannot be tested. The possibility also remains that these patients may represent a form of allelic heterogeneity for DM. In the fragile $\mathrm{X}$ syndrome of mental retardation, another of the trinucleotide repeat disorders, a case has been reported in which a point mutation within the FMR1 gene resulted in a phenotype identical to that caused by the trinucleotide expansion. ${ }^{25}$ However, in the patients presented here exonic sequencing of the entire DMPK gene failed to identify any mutations. Although we have not formally excluded the possibility of an abnormal intronic splice site mutation in these patients, our data suggest that mutations within the DMPK gene itself are unlikely to be the cause of a significant number of cases of clinical DM in which there is no CTG expansion. We are currently attempting to identify genes which are closely related to DMPK at the DNA sequencing level, and these will be analysed as potential candidates for these cases and PROMM-like patients. It will also be important to confirm that these patients do not represent somatic mosaics, in whom there has been an expansion of the CTG repeat in the affected tissues.

Work at Charing Cross and Westminster Medical School is funded by the Muscular Dystrophy Group of Great Britain, and the Central Research Fund of the University of London.

1 Harper PS. Myotonic dystrophy. 2nd ed. London: Saunders, 1989.

2 Howeler CJ, Busch HFM, Geraedts JPM, Niermeijer MF, Staal A. Anticipation in myotonic dystrophy; fact or fiction. Brain 1989;112:779-97.

3 Shelbourne P, Johnson K. Myotonic dystrophy: another case of too many repeats? Hum Mutat 1992;1:183-9.

4 Brunner HG, Nillesen W, van Oost BA, et al. Presymptomatic diagnosis of myotonic dystrophy. $\mathfrak{f}$ Med Genet 1992;29:780-4

5 Lavedan C, Hoffman-Radvanyi H, Shelbourne $\mathrm{P}$, et al. Myotonic dystrophy: size and sex dependent dynamics of CTG meiotic instability and somatic mosaicism. $A m \mathcal{f}$ Hum Genet 1993;52:875-83.

6 Redman JB, Fenwick RG, Fu YH, Pizzuti A, Caskey CT. Relationship between parental trinucleotide repeat length and severity of myotonic dystrophy in offspring. $¥ A M A$ 1993;269:1960-5.

7 Shelbourne P, Winquist R, Kunert E, et al. Unstable DNA may be responsible for the incomplete penetrance of the 467-73.

8 Abeliovich D, Lerer I, Pashut-Lauron I, et al. Negative expansion of the myotonic dystrophy unstable sequence. expansion of the myotonic dystrophy

9 Cobo AM, Baiget M, Lopez de Munain A, Poza JL, Johnson Kobo AM, Baiget M, Lopez de Munain A, Poza JL, Johnson
KJ. Sex-related difference in intergenerational expansion KJ. Sex-related difference in intergenerational expans
of myotonic dystrophy gene. Lancet 1993;341:1159.

10 Shelbourne P, Davies J, Buxton J, et al. Direct diagnosis of Shelbourne P, Davies J, Buxton J, et al. Direct diagnosis of
myotonic dystrophy with a disease-specific DNA marker.

11 Barcelo JM, Mahadevan MS, Tsilfidis C, MacKenzie AE, Korneluk RG. Intergenerational stability of the myotonic dystrophy protomutation. Hum Mol Genet 1993;2:705-9. 12 Aslanidis C, Jansen G, Amemiya C, et al. Cloning of the 
essential myotonic dystrophy region and mapping of the putative defect. Nature 1992;355:548-51.

13 Buxton J, Shelbourne P, Davies J, et al. Detection of an to individuals with myotonic dystrophy. Nature 1992;355:547-8.

14 Harley HG, Brook JD, Rundle SA, et al. Expansion of an unstable DNA region and phenotypic variation in an unstable DNA region and phenotypic

15 Miller SA, Dykes DD, Polesky HF. A simple salting out procedure for extracting DNA from human nucleated cells. Nucleic Acids Res 1988;16:1215.

16 Feinberg AP, Vogelstein B. A technique for radiolabeling DNA restriction endonuclease fragments to high specific activity. Anal Biochem 1983;132:6.

17 Brook JD, McCurrach ME, Harley HG, et al. Molecular basis of myotonic dystrophy: expansion of a trinucleotid (CTG) repeat at the $3^{\prime}$ end of a protein kinase family member. Cell 1992;68:799-808.

18 Griggs R, Wood D, Moxley R, et al. Criteria for establishing the validity of genetic recombination in myotonic dystrophy. Neurology 1989;39:420-41.

19 Koch MC, Grimm T, Harley HG, Harper PS. Genetic risks for children of women with myotonic dystrophy. $A m \mathcal{F}$ Hum Genet 1991;48:1084-91.

20 Ashizawa $\mathrm{T}$, Anvret $\mathrm{M}$, Baiget $\mathrm{M}$, et al. Characteristics of intergenerational contractions of the CTG repeat in myotonic dystrophy. Am $¥$ Hum Genet 1994;54:414-23.

21 Anvret $M$, Ahlberg $G$, Grandell $U$, et al. Larger expansions of the CTG repeat in muscle compared to lymphocytes from patients with myotonic dystrophy. Hum Mol Genet 1993;2:1397-400

22 Thornton CA, Johnson K, Moxley RT III. Myotonic dystrophy patients have larger CTG expansions in skeletal muscle than in leukocytes. Ann Neurol 1994;35:104-7.

23 Imbert G, Kretz C, Johnson K, Mandel JL. Origin of the expansion mutation in myotonic dystrophy. Nature Genet 1993;4:72-6.

24 Ricker K, Koch MC, Lehmann-Horn F, et al. Proximal myotonic myopathy: a new dominant disorder with myotonia, muscle weakness, and cataracts. Neurology 1994; 44:1448-52.

25 De Boulle K, Verkerk AJMH, Reyniers E, et al. A point mutation in the FMT-1 gene associated with fragile $\mathrm{X}$ mental retardation. Nature Genet 1993;3:31-5. 